\title{
AMADURECIMENTO DE FILTROS LENTOS DE AREIA E REMOÇÃo DE MICRORGANISMOS INDICADORES DE QUALIDADE DA ÁGUA AO LONGO DA PROFUNDIDADE DO LEITO: UMA AVALIAÇÃO EM INSTALAÇÃO PILOTO
}

\author{
Maturation of SLOW SAND FILTERS AND REMOVAL OF MICROORGaNISMS' \\ INDICATORS OF WATER QUALITY ALONG THE MEDIA DEPTH: AN EVALUATION \\ IN PILOT PLANT
}

LUDMILA LADEIRA ALVES DE BRITO

Bióloga. Mestre em Saneamento, Meio Ambiente e Recursos Hídricos. Bióloga do IBAMA

\author{
ALLISSON BADARO CARDOSO \\ Engenheiro civil. Bolsista do CNPq \\ Daniella Pedrosa SaLVAdor \\ Bióloga. Bolsista da FAPEMIG
}

\section{LÉO HELLER}

Engenheiro civil. Mestre em Engenharia Sanitária. Doutor em Epidemiologia. Professor do Departamento de Engenharia Sanitária e Ambiental - UFMG

Recebido: 19/01/05 Aceito: 28/09/05

\section{RESUMO}

O potencial da filtração lenta como opção tecnológica para o tratamento de água nos países em desenvolvimento e sua capacidade de remoçãa de contaminantes, sobretudo patogênicos, são reconhecidos. Contudo, ainda permanece incompleto o conhecimento acerca dos mecanismos que predominantemente atuam na remoção dos microrganismos. Objetivando avançar nessa compreensão, desenvolveu-se uma investigação experimental, em unidades piloto, em filtros lentos de areia com escoamento descendente e ascendente, operados com água sintética e duas taxas de filtração $\left(3 \mathrm{e} 6 \mathrm{~m}^{3} / \mathrm{m}^{2} \mathrm{~d}\right)$. A retenção dos microrganismos indicadores foi avaliada em cinco camadas, com $0,15 \mathrm{~m}$ de espessura cada, em dois momentos da carreira. A maturidade biológica do leito filtrante foi menos favorecida pela taxa mais alta de filtração e pelo fluxo ascendente. Os $0,45 \mathrm{~m}$ iniciais do leito filtrante foram importantes na remoção de microrganismos sob as condiçôes estudadas, mas a remoção não se restringiu a estas camadas, tendo sido observada para todos os indicadores retenção nas camadas de 0,45-0,60 m e de 0,60-0,75 m. A schmutzdecke parece desempenhar papel efetivo na remoção de indicadores microbiológicos apenas quando bem desenvolvida. Há uma indicação de que a camada suporte exerce algum papel na retenção de sólidos e microrganismos no fluxo ascendente.

PALAVRAS-CHAVE: Filtração lenta, schmutzdecke, Clostridium perfringens, endosporos, Bacillus subtilis, turbidez.

\begin{abstract}
The potential of the slow sand filtration as technological option for drinking-water treatment in developing countries and its capacity of contaminants removal, mainly pathogens, are recognized. However, the knowledge concerning the predominant mechanisms that act in microorganism's removal still remains incomplete. Aiming to advance in the understanding of these themes, an experimental investigation was carried out, working with pilot plants of downflow and upflow slow sand filters, operated with synthetic water and two filtration rates ( 3 and $6 \mathrm{~m}^{3} / \mathrm{m}^{2}$.d). The microorganisms indicators removal was evaluated in five layers, with $0.15 \mathrm{~m}$ of thickness each, in two run phases. The biological maturation of the filter media was less favoured by the highest rate and by the upflow filter. The initial $0.45 \mathrm{~m}$ of the filter media were important in the microorganism's removal in the conditions evaluated, but removal was not limited to these layers, since all indicators were retained also in 0.45-0.60 m and 0.60-0.75 m layers, in different proportions among the filter runs. The schmutzdecke seems to play an effective role in the microbiological indicators removal only when well developed. an indication of the role of the support layer in solids and microorganisms retention was observed in the upflow filter.
\end{abstract}

KEYWORDS: Slow sand filter, schmutzdecke, Clostridium perfringens, endospores, Bacillus subtilis, turbidity. 


\section{INTRODUÇÃO}

A filtração lenta, em uso há mais de 170 anos, em razão de seu potencial como opção tecnológica para o tratamento de água nos países em desenvolvimento, ainda necessita de um mais aprofundado conhecimento sobre os mecanismos de remoção de contaminantes. Em especial em relação à remoção dos denominados patogênicos emergentes, esse conhecimento mostra-se importante, de forma a se obterem elementos para a otimização do processo nessa função.

Diversos autores (Huisman, 1982; Vargas, 1999) vêm relatando que, na remoção de microrganismos pelo filtro, atuam não apenas o processo natural de peneiramento, mas uma conjunção de fatores físicos, químicos e, sobretudo, microbiológicos, tais como a predação, a competição, a morte natural e a necrofagia. O conhecimento desses mecanismos aponta para uma potencialmente satisfatória remoção de bactérias, vírus, além de cistos de Giardia e oocistos de Cryptosporidium. Contudo, para tanto, mostra-se necessário entender como se processa espacialmente a remoção destes patógenos no interior dos filtros, contribuindo para esclarecer os mecanismos de retenção e direcionar as decisōes de projeto e operacionais, de modo a se ampliar a segurança do processo.

Vários foram os estudos realizados para avaliação da eficiência de filtros lentos na remoção de microrganismos patogênicos e indicadores de contaminação, sendo que na maioria puderam ser observados elevadas taxas de remoção. Por exemplo, Fox et al (1984) reportaram remoção consistente de 4 a $5 \log$ de coliformes totais em filtros em escala piloto. Bellamy et al (1985), também estudando filtros piloto, encontraram remoção acima de $99 \%$ para coliformes totais e termotolerantes, resultado confirmado por Murtha e Heller (2003), que em cerca de $90 \%$ dos resultados encontraram valores nulos de concentração de $E$. coli no efluente de filtros pilotos. Poynter e Slade (1977) obtiveram remoção de vírus de até 99,997\%, sendo que, aliado aos altos índices de remoção, foi determinado que apenas $2 \%$ dos vírus afluentes ao filtro permanecem viáveis na camada de areia (McConnel, 1984).

A importância da maturidade do leito filtrante fica evidenciada em pesquisa em escala piloto (Bellamy et al, 1985), em que um novo filtro removeu $0,82 \mathrm{log}$ de coliformes totais e cerca de 1,7 log de
Giardia. Quando uma população microbiana se estabeleceu no interior do leito de areia, após duas semanas, a remoção de coliformes totais elevou-se para 4 log e não mais se identificou Giardia na água filtrada. Entretanto, não existe ainda um consenso sobre um indicador que melhor traduza a maturidade biológica de filtros lentos de areia. Bellamy et al (1985), apesar de terem escolhido as bactérias heterotróficas totais como medida de maturidade, afirmam que o melhor indicativo é a qualidade do efluente, que passa a ser constante a partir de certo momento da carreira, correspondente ao alcance do equilíbrio pela comunidade microbiana. Sánchez et al (1999b), avaliando a perturbação das diversas técnicas de limpeza de um filtro lento descendente sobre a maturidade do leito, afirmam que a avaliação quantitativa e qualitativa de algas e protozoários que formam o biofilme fornece boas informações sobre o desenvolvimento da camada biológica no interior do leito de areia.

Alguns estudos buscaram avaliar a remoção de indicadores em profundidade, como o trabalho de Murtha eHeller (2003), mostrando que os $0,30 \mathrm{~m}$ iniciais do leito filtrante seriam responsáveis por quase a totalidade de remoção de coliformes totais e E. coli. Timms et al (1995) observaram que apenas os $2,5 \mathrm{~cm}$ iniciais do leito de areia do filtro retinham oocistos de Cryptosporidium. $\mathrm{Na}$ realidade, os poucos estudos publicados retratam situações particulares de maturidade do leito filtrante, temperatura $\mathrm{e}$ taxa de filtração, dentre outros aspectos, dificultando a generalização dos resultados.

Por outro lado, dadas as dificuldades e o custo para análise laboratorial de patogênicos, mostra-se importante a identificação de indicadores que possibilitem uma mais ágil e operacional avaliação da sua eficiência, bem como para o desenvolvimento de planos de monitoramento adequados. Logo, compreender o comportamento dos microrganismos indicadores utilizados na avaliação da eficiência do processo de filtração e entender o efeito do tratamento sobre eles mostra-se prioritário para a proteção à saúde humana.

Indicadores físicos, como a turbidez e a contagem de partículas, e micro biológicos têm sido propostos para representarem cistos e oocistos de protozoários. Dentre os microbiológicos, destacam-se as tradicionais bactérias do grupo coliformes; os esporos de bactérias anaeróbias e o Clostridium perfringens; os esporos de bactérias aeróbias e o Bacillus subtilis e a contagem de bactérias heterotróficas totais.
Pela sua resistência, a presença de Clostridium perfringens no efluente de uma estação de tratamento de água pode significar que existam deficiências na filtração (WHO, 2004; Araujo et al, 2001). No entanto, Nieminski et al (2000) constataram que esses esporos normalmente se apresentam em concentraçōes muito baixas na água bruta para serem usados como indicadores da eficiência do tratamento. Ferguson et al (1996), estudando vários indicadores para presença de protozoários em águas de superfície, observaram que o único microrganismo a apresentar correlação com Cryptosporidium e Giardia foi Clostridium perfringens, enquanto Nieminski et al (2000) não observaram nenhuma correlação destes protozoários $\operatorname{com} C$. Perfringens ou com a contagem total de esporos anaeróbios.

Os esporos de bactérias aeróbias vêm sendo recomendados como um indicador de performance do tratamento em remover cistos e oocistos de protozoários, já que apresentam resistência a pressões ambientais, à temperatura e a vários compostos normalmente usados na desinfecção da água (Barbeau et al, 1999). Os estudos de Rice et al (1996) e de Nieminski et al (2000) apontaram que os esporos de bactérias aeróbias indígenos não foram satisfatórios em indicar a presença dos protozoários em mananciais, mas, atrelados a outros indicadores como turbidez e contagem de partículas, foram eficientes indicadores da qualidade do tratamento.

As bactérias heterotróficas totais são normalmente utilizadas como indicadores para avaliação do conteúdo geral de bactérias na água. Nieminski et al (2000) salientam que, apesar de se apresentarem em altas concentrações na água bruta, é reconhecido que estes microrganismos são capazes de crescer no interior dos filtros de areia, impedindo seu uso como indicador da eficiência do processo de tratamento. Porém, Bellamy et al (1985) e Ellis e Aydin (1995), estudando o comportamento de filtros lentos sob diversas condições ambientais e operacionais, optaram pelas bactérias heterotróficas totais como indicador da maturidade biológica do leito filtrante.

Em vista desse estado de conhecimento, o presente trabalho objetivou contribuir para avançar a compreensão sobre a dinâmica dos microrganismos indicadores de qualidade de água ao longo da profundidade do leito filtrante de filtros lentos de areia, bem como sobre a matu- 
ridade biológica dos filtros lentos em diferentes etapas da carreira de filtração, comparando diferentes taxas e dois sentidos de fluxo no filtro. Apresenta-se neste artigo parte de um trabalho mais amplo, que privilegiou a avaliação do comportamento de cistos de Giardia e de oocistos de Cryptosporidium no interior do leito de filtros lentos de areia (Brito, 2002).

\section{MATERIAL E MÉTODOS}

\section{Aparato experimental}

A instalação avaliada está representada na Figura 1, sendo composta por filtros de carvão ativado, caixa de preparo de água, bomba para transferência da caixa de preparo para a caixa de alimentação, caixa de alimentação, bomba peristáltica para alimentação dos filtros, filtro lento descendente (FLD), filtro lento ascendente (FLA) e quadros piezométricos.

Cada filtro era constituído de dois tubos flangeados de acrílico superpostos, de 0,20 m de diâmetro e 1,50 $\mathrm{m}$ de altura. Na parte inferior de cada filtro foi fixada uma placa perfurada para sustentação dos leitos granulares, localizada a $0,10 \mathrm{~m}$ da base.

No filtro lento descendente, a entrada de água localizava-se a $0,30 \mathrm{~m}$ abaixo da borda superior do filtro $(1,45 \mathrm{~m}$ acima do leito filtrante) e a saída logo abaixo da placa perfurada, com a forma de " $U$ " invertido, visando manter um nível mínimo de água sobre o leito de $0,45 \mathrm{~m}$. Já no filtro lento ascendente, a entrada dava-se $0,10 \mathrm{~cm}$ acima da base inferior do filtro e a saída a $0,30 \mathrm{~cm}$ abaixo da borda superior $(1,45 \mathrm{~m}$ acima do leito filtrante).

O leito filtrante de ambos os filtros foi constituído por areia, com espessura de $0,75 \mathrm{~m}$, tamanho efetivo de $0,25 \mathrm{~mm}$, coeficiente de uniformidade de 2,40 , diâmetro mínimo de 0,084 mm e diâmetro máximo de $1,00 \mathrm{~mm}$. A camada suporte constituiu-se de três camadas de seixos rolados, de granulometria variando entre 1,20 e 19,10 mm.

\section{Água de estudo}

Os filtros foram alimentados com água sintética, com características físicas compatíveis com o tratamento pelo processo de filtração lenta e com concentrações elevadas de microrganismos, de tal forma a assegurar a sensibilidade do experimento, conforme descrito a seguir:

- turbidez: $15+/-5$ UNT;

- cor verdadeira: $15+/-5 \mathrm{uC}$;

- pH: 6,5 - 7,5;

- coliformes totais: $10^{5}-10^{6} \mathrm{NMP} / 100 \mathrm{~mL}$; - Escherichia coli: $10^{3}-10^{4} \mathrm{NMP} / 100 \mathrm{~mL}$; - esporos de bactérias anaeróbiase Clostridium perfringens: $10^{1}-10^{2} \mathrm{UFC} / 100 \mathrm{~mL}$;

- esporos de bactérias aeróbias e Bacillus subtilis: $10^{4}-10^{5} \mathrm{UFC} / 100 \mathrm{~mL}$;

- Cryptosporidium: $10^{1}-10^{2}$ oocistos/L;

- Giardia: $10^{0}-10^{1}$ cistos/L.

Para o preparo da água sintética, foi captada água da rede pública, que foi posteriormente desclorada por filtros de carvão ativado e nela acrescentados: - bentonita, para geração de turbidez; - infusão de erva mate, para produção de cor verdadeira;

- ácido sulfúrico $1 \mathrm{~N}$ para correção de $\mathrm{pH}$; - alíquota de esgoto, que forneceu os microrganismos analisados (coliformes totais, Escherichia coli, esporos de bactérias anaeróbias e Clostridium perfringens, esporos de bactérias aeróbias e Bacillus subtilis, cistos de Giardia);

- oocistos de Cryptosporidium, produzidos em um bezerro neonato.

\section{Delineamento experimental e amostragem}

Cada um dos filtros (FLD e FLA) foi avaliado sob duas diferentes taxas de filtração $-3 \mathrm{~m}^{3} / \mathrm{m}^{2}$.d e $6 \mathrm{~m}^{3} / \mathrm{m}^{2}$.d - gerando quatro combinaçôes. Para cada uma destas situaçōes foram realizadas duas carreiras (duplicata), totalizando oito carreiras de filtração, quatro para cada filtro.

As análises foram realizadas duas vezes durante a carreira de cada filtro, uma no início da carreira, quando o filtro ainda não está completamente maduro biologicamente, e outra após sua estabilizaçâo, verificada através da qualidade do efluente, conforme Tabela 1.

Estes momentos foram escolhidos baseando-se em experimentos anteriores (Vieira, 2002), que determinaram a duração da carreira dos filtros e a fase quando passam a produzir efluente estável, com turbidez abaixo de 2 UNT, valor estabelecido pela Portaria 518/2004 (Brasil, 2004).

Para a análise, a carreira de filtração era interrompida por meio do desligamento do sistema de alimentação do filtro. A água sobrenadante no filtro era retirada pela parte de cima da unidade, com o auxílio de uma bomba peristáltica, até se atingir o topo do leito filtrante. No FLD os últimos $0,10 \mathrm{~m}$ de água sobre a camada eram retirados utilizando-se um sifāo, para evitar perturbação do biofilme sobre a camada de areia (schmutzdecke). Em seguida, o filtro era desmontado e a coluna superior retirada. No FLD foi inicialmente raspada a schmutzdecke (Figura 2), que foi avaliada tanto para a presença dos protozoários estudados, como para os microrganismos indicadores pesquisados.

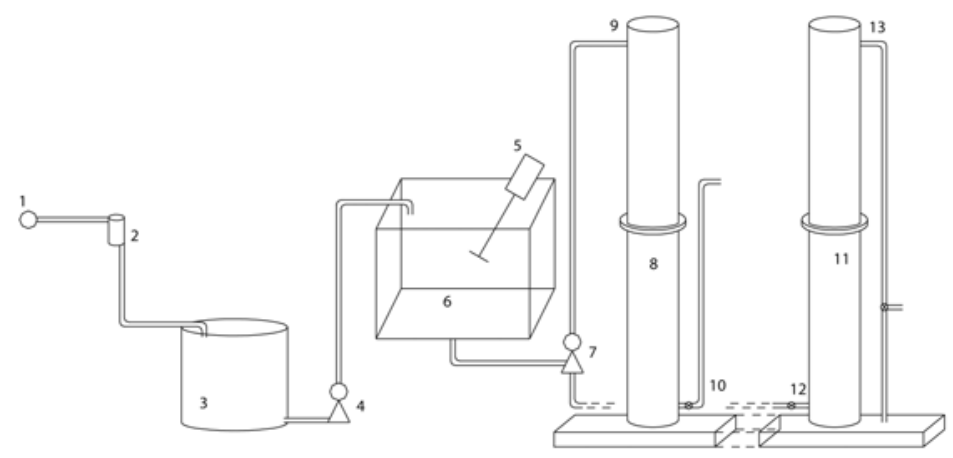

\section{LEGENDA}

1. Entrada de água da rede

2. Filtro de Carvão Ativado

3. Caixa de preparação de água bruta $-250 \mathrm{~L}$

4. Bomba centrífuga

5. Misturador

6. Caixa de armazenamento de água bruta (500 L)

7. Bomba peristáltica para alimentação dos filtros

8. FLD

9. Entrada de água bruta no FLD

10. Saída de água filtrada do FLD

11. FLA

12. Entrada de água bruta no FLA

13. Saída de água filtrada do FLA

Figura I - Esquema da planta piloto 
Tabela I - Momentos de análise em cada carreira

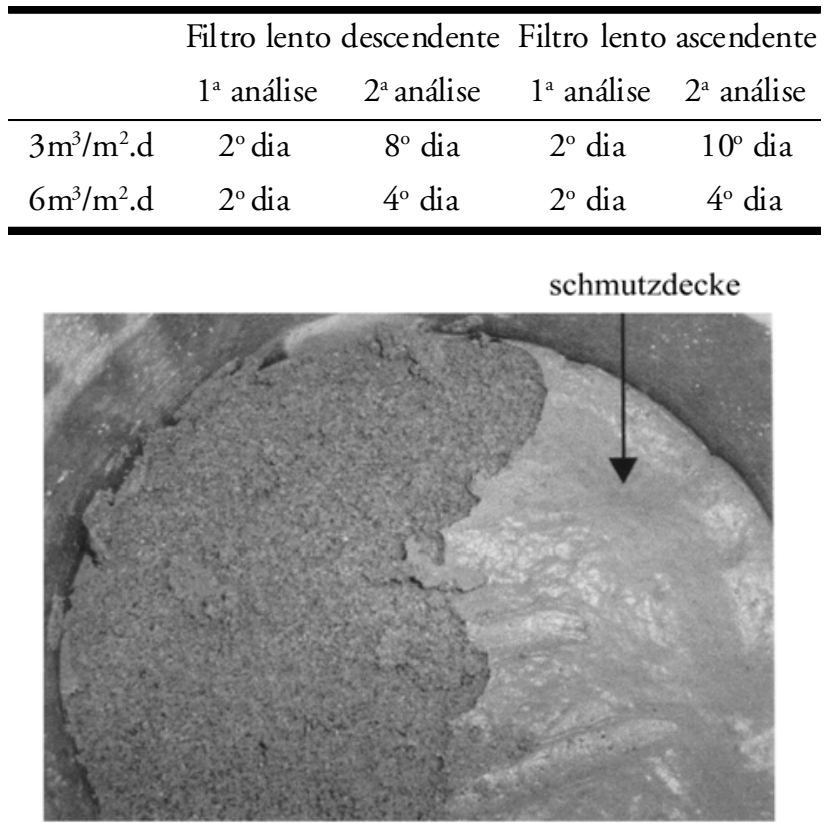

Figura 2 - Raspagem da schmutzdecke

O leito de areia foi divido em cinco camadas (Figura 3) de 0,15 m de espessura, que foram retiradas com o auxílio de uma concha, previamente desinfetada em solução de hipoclorito de sódio concentrado. Todo o material de cada camada era lavado seqüencialmente em água destilada estéril e em solução de tiossulfato de sódio a $10 \%$ estéril. Seu conteúdo era disposto em vasilhames de volume igual a $15 \mathrm{~L}$, igualmente desinfetados (Figura 4).

Cada camada foi lavada com $11 \mathrm{~L}$ de água destilada estéril, da seguinte maneira: (i) adicionava-se 1 a $2 \mathrm{~L}$ de água destilada estéril; (ii) agitava-se com a própria concha usada na retirada da camada; (iii) a água era então vertida e armazenada. O procedimento era repetido por aproximadamente seis vezes. A água obtida era então homogeneizada e destinada às análises.

Retirado todo o leito filtrante, a camada suporte era lavada por meio da injeção ascendente de água desclorada em alta pressão. Esta lavagem só era interrompida quando o efluente da lavagem estivesse com muito baixa turbidez.

Após todo o procedimento, a areia lavada era recolocada no filtro e a carreira reiniciada, sob as mesmas condiçôes, até a segunda amostragem, que se procedeu da mesma maneira.

\section{Monitoramento}

A pesquisa monitorou um conjunto maior de parâmetros que os discutidos neste artigo. Turbidez, cor aparente e cor verdadeira foram avaliadas diariamente na água bruta e no efluente dos filtros. $\mathrm{Nas}$ camadas de areia foram avaliados turbidez, cor aparente e verdadeira, $\mathrm{pH}$ e série de sólidos. Foram avaliados ainda na água bruta cloro total e cloro livre, para a verificação da eficiência dos filtros de carvão ativado na remoção deste componente.

Foram avaliados os seguintes parâmetros microbiológicos na água bruta, no

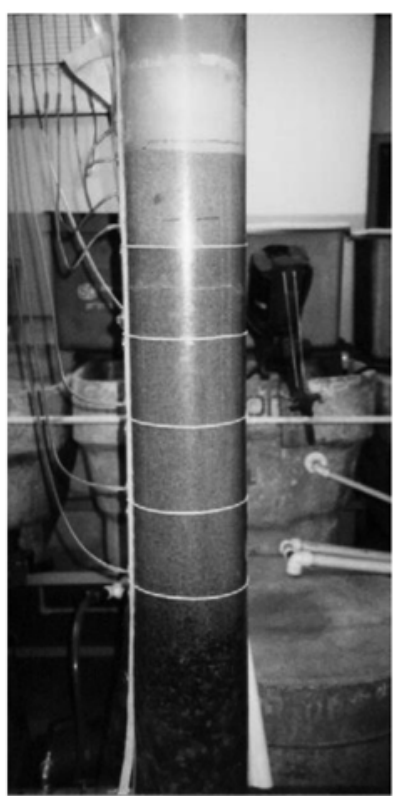

Figura 3 - Filtro dividido em cinco camadas de $0,15 \mathrm{~m}$ efluente, nas camadas de areia e na schmutzdecke do FLD:

- coliformes totais;

- Escherichia coli;

- esporos de bactérias anaeróbias e Clostridium perfringens;

- esporos de bactérias aeróbias e Bacillus subtilis:

- bactérias heterotróficas totais (HPC);

- oocistos de Cryptosporidium sp e cistos de Giardia sp.

Coliformes totais e Escherichia coli foram realizadas pela técnica do substrato cromogênico, utilizando-se o meio de cultura Colilert ${ }^{\circledR}$. A análise de bactérias heterotróficas totais foi realizada pela técnica de pour-plate, descrita na seção 9215B do Standard Methods for the Examination of Water and Wastewater (APHA et al, 1998). A análise de esporos de bactérias anaeróbias e Clostridium perfringens e de bactérias aeróbias e Bacillus subtilis foi realizada pela técnica da membrana filtrante, utilizando-se respectivamente os meios Ágar mCP modificado (Nieminski et al, 2000) e Ágar Azul de Tripan com $1 \%$ de amido (Nieminski et al, 2000).

Para a análise dos parâmetros bacteriológicos na schmutzdecke, em cada experimento $2 \mathrm{~g}$ do material foram coletadas e ressuspendidos em $250 \mathrm{~mL}$ de água destilada estéril. Após a homogeneizaçāo desta suspensão, as análises eram realizadas pelas mesmas técnicas descritas anteriormente para as amostras de água.

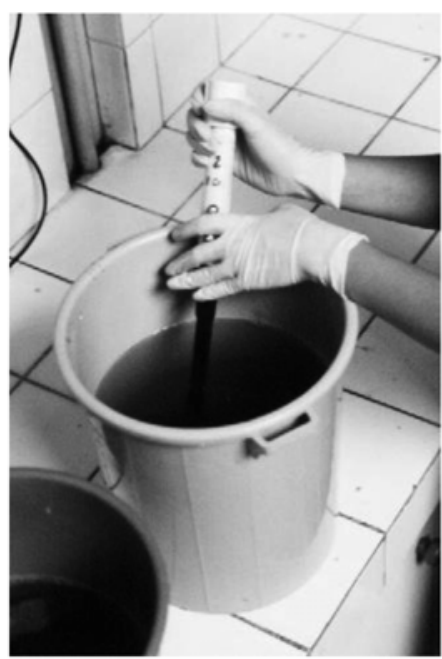

Figura 4 - Lavagem das camadas de areia 


\section{Análise dos dados}

Os dados obtidos para as diferentes situações estudadas, dois para cada cama$\mathrm{da}$, foram avaliados qualitativamente e mediante comparação gráfica, em vista do número de dados disponíveis.

\section{RESULTADOS E DISCUSSÃO}

\section{Avaliação da maturidade do leito filtrante}

\section{(a) Avaliação em profundidade}

A avaliação da maturidade biológica do leito filtrante procedeu-se fundamentalmente mediante a pesquisa de bactérias heterotróficas totais. A Figura 5 apresenta a quantidade de bactérias heterotróficas totais no FLD, para todas as situaçôes estudadas, enquanto a Figura 6 demonstra os mesmo dados para o FLA.
Para a taxa de filtração de $6 \mathrm{~m}^{3} / \mathrm{m}^{2}$.d, a análise do segundo momento da carreira (quatro dias para o FLD e dez dias para o FLA) mostrou uma maior concentração de bactérias heterotróficas totais em todas as camadas, de forma mais acentuada no FLD. Isto pode indicar que, devido ao grande aporte de bactérias e à velocidade de filtração, há um predomínio de bactérias heterotróficas no biofilme formado no leito filtrante, com um número escasso de agentes que determinem o controle do crescimento destas populaçôes. Ao se analisar a taxa de filtração mais baixa, percebe-se que pouca diferença existe entre o primeiro (dois dias) e o segundo momento da carreira (oito dias para o FLD e dez dias para o FLA), o que pode ser uma indicação de que o biofilme formado neste momento é mais bem equilibrado, exercendo controle sobre o número de bactérias pela presença de competidores (algas e outras bactérias) e/ou predadores (principalmente protozoários e rotíferos) (Lloyd, 1973; Sánchez et al, 1999a). De acordo com Lloyd (1973), com o passar do tempo, diminui o número de colônias bacterianas no interior do filtro e aumenta o número de protozoários ciliados, principalmente de espécies do gênero Vorticella, reconhecidamente predadores de bactérias em suspensão.

É consenso entre diversos autores que a colonização do leito de areia de filtro lento é função de uma série de fatores conjugados, como a concentração de nutrientes e matéria orgânica na água bruta, temperatura ambiente, quantidade de bactérias presentes no afluente, condiçôes operacionais, dentre outras (Huisman, 1982; Bellamy et al, 1985; Sánchez et al, $1999 b)$. A taxa de filtração de $3 \mathrm{~m}^{3} / \mathrm{m}^{2}$.d determina que as velocidades de escoamento no interior do leito filtrante sejam menores, facilitando assim a atuação dos mecanismos de transporte e conseqüente formação do biofilme. Esta comunidade biológica desenvolve-se sob condições hidráulicas mais favoráveis, mas dispõe de uma concentração afluente de matéria

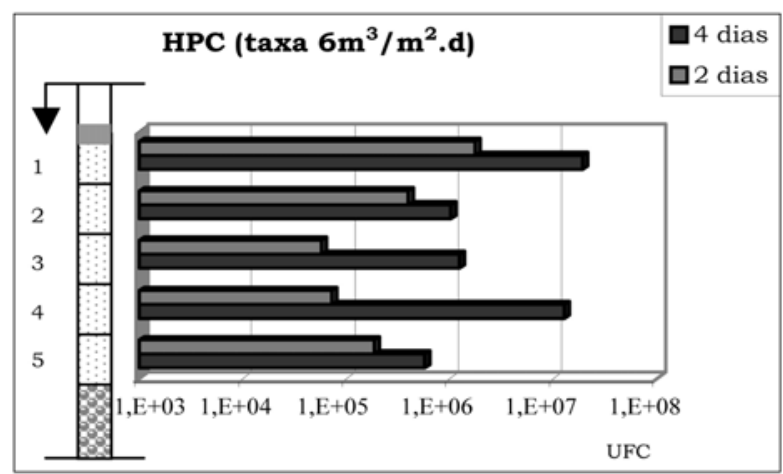

(a)

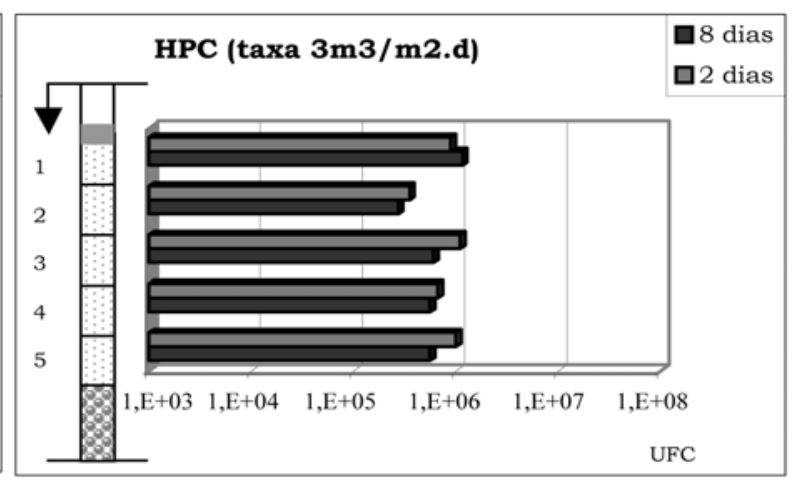

(b)

Figura 5 - Quantidade de bactérias heterotróficas totais ao longo do leito filtrante do FLD. (a) taxa de filtração: $6 \mathrm{~m} / \mathrm{m}$.d; (b) taxa de filtração: $3 \mathrm{~m} / \mathrm{m}^{2}$.d. (espessura de cada camada: 0, I5 m)

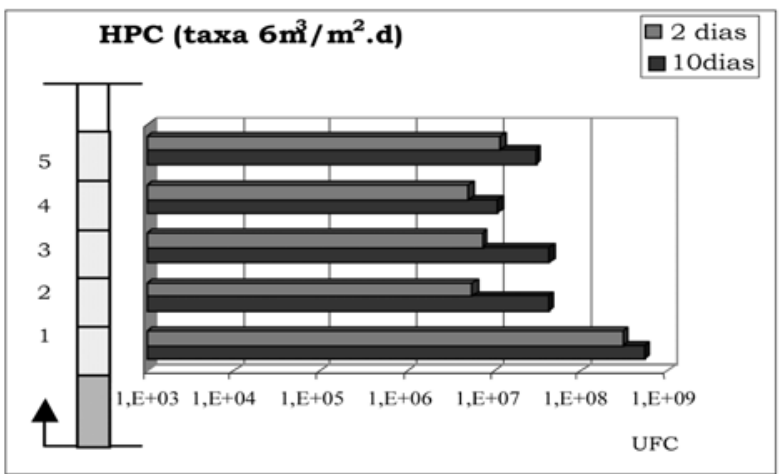

(a)

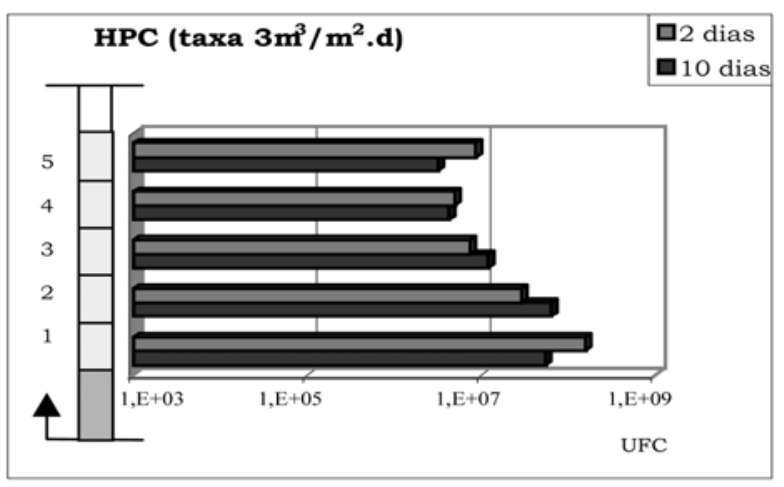

(b)

Figura 6 - Quantidade de bactérias heterotróficas tơtais ao longo do leito filtrante do FLA. (a) taxa de filtração: $6 \mathrm{~m}^{3} / \mathrm{m}^{2}$.d; (b) taxa de filtração: $3 \mathrm{~m} / \mathrm{m}^{2}$.d. (espessura de cada camada: $0,15 \mathrm{~m}$ ) 
orgânica e nutrientes mais baixa, tornando o ambiente mais seletivo para o desenvolvimento de microrganismos.

Quanto maior o tempo de carreira, maior o equilíbrio alcançado entre as diversas populaçóes que colonizam o filtro, em um mesmo segmento ou em diferentes profundidades (Sánchez et al, 1999a). No entanto, para se alcançar um equilíbrio satisfatório, os períodos de duração adotados nesta pesquisa podem ter sido insuficientes. Fox et al (1984) afirmam ser necessários prazos maiores, de até vários meses, para a maioria dos filtros em escala real, ou mesmo em escala piloto. Os prazos adotados neste experimento foram balizados principalmente na qualidade do efluente, em termos de turbidez, assumindo-se que a produção estável de um efluente adequado significaria que o filtro teria alcançado a maturidade microbiológica.

As condiçōes ambientais sob as quais ocorre a filtração são também de extrema importância para um bom desenvolvimento da camada biológica, sendo a temperatura a mais relevante dentre elas. $\mathrm{O}$ período no qual foi desenvolvido o presente estudo (setembro a dezembro de 2001) apresentou sempre temperaturas elevadas no interior do Laboratório de Instalaçōes Piloto, onde se desenvolveu o experimento, com média no período de $28,9^{\circ} \mathrm{C}$, bem mais alta do que aquela utilizada na maioria dos estudos reportados na literatura. Ainda assim, as concentraçóes de bactérias por grama de areia obtidas nesta pesquisa não são superiores às reportadas em alguns trabalhos, uma vez que se referem a apenas uma carreira, enquanto os demais analisaram a areia após uma série de carreiras (Tabela 2).

$\mathrm{Na}$ Figura 7 é realizada comparação entre os momentos de análise na carreira

Tabela 2 - Concentração de bactérias heterotróficas totais (UFC/ grama de areia) em Filtros Lentos Descendentes, segundo três referências

\begin{tabular}{cccc}
\hline Profundidade & Presente trabalho* & $\begin{array}{c}\text { Seelaus et al } \\
(1986)^{* *}\end{array}$ & $\begin{array}{c}\text { Ellis \& Aydin } \\
(1995))^{* * *}\end{array}$ \\
\hline $0-0,15 \mathrm{~m}$ & $3,17 \times 10^{5}$ & $4,45 \times 10^{7}$ & $3,84 \times 10^{8}$ \\
$0,15-0,30 \mathrm{~m}$ & $1,68 \times 10^{2}$ & $3,0 \times 10^{7}$ & $2,47 \times 10^{7}$ \\
$0,30-0,60 \mathrm{~m}$ & $4,13 \times 10^{2}$ & - & $3,38 \times 10^{7}$ \\
$0,60-0,75 \mathrm{~m}$ & $1,25 \times 10^{3}$ & - & $8,06 \times 10^{6}$ \\
$0,60-1,20 \mathrm{~m}$ & - & - & $6,34 \times 10^{6}$ \\
\hline
\end{tabular}

* Taxa $6 \mathrm{~m}^{3} / \mathrm{m}^{2} . \mathrm{d}, 4$ dias de carreira;

**Taxa $6,24 \mathrm{~m}^{3} / \mathrm{m}^{2} . \mathrm{d}, 113$ dias de carreira;

***Taxa variando de $2,4-12 \mathrm{~m}^{3} / \mathrm{m}^{2}$.d; Temperatura variando de $5^{\circ} \mathrm{C}$ a $25^{\circ} \mathrm{C} ; 2$ anos de experimento; várias raspagens do leito e reposição imediata com areia limpa.

Nota: adotado $1 \mathrm{~cm}^{3}$ de areia $=2,6 \mathrm{~g}$

e os dois diferentes sentidos de fluxo. Para a taxa mais alta, há uma grande similaridade entre os filtros no primeiro momento de análise (dois dias); já no segundo momento, o FLD apresenta concentrações maiores de bactérias heterotróficas totais que o FLA, talvez pela contribuição da camada suporte deste filtro na remoção de microrganismos. Para a taxa de $3 \mathrm{~m}^{3} / \mathrm{m}^{2}$.d observa-se uma pequena diferença nas camadas 3 , 4 e $5(0,30-0,45 \mathrm{~m}$, 0,45-0,60 m e 0,60-0,75 m respectivamente): no FLA, a concentração cai ligeiramente da camada 2 para a 3 , enquanto no FLD este valor permanece na mesma ordem de grandeza que as camadas anteriores.

A Tabela 3 apresenta a porcentagem do total acumulado no filtro de cada uma das camadas analisadas, em todas as carreiras realizadas durante o experimento.

De acordo com a literatura, os $0,40 \mathrm{~m}$ iniciais do leito filtrante seriam os principais responsáveis pela remoção dos mi- crorganismos, estando concentrada nesta porção toda a atividade microbiana no leito filtrante (Huisman, 1982; Bellamy et al, 1985; Di Bernardo, 1993; Di Bernardo et al, 1999; Vargas, 1999). Com exceção das carreiras C3-2D e C41D para o FLD e da carreira C3 do FLA, a retenção de bactérias heterotróficas totais esteve acima de $90 \%$ (média de 95,8\% para o FLD e $94,34 \%$ para o FLA). No FLD, a primeira camada e a schmutzdecke, principalmente, foram as responsáveis pela retenção de bactérias heterotróficas. $\mathrm{Na}$ carreira C3-2D e nas carreiras C3-1A e C3-2A houve uma maior penetração destas bactérias, provavelmente devido à maior taxa de filtração empregada.

Em biofilmes, um dos meios de controle do crescimento populacional é o desprendimento da camada biológica do substrato, cuja taxa é proporcional ao crescimento de biomassa aderida e às forças hidrodinâmicas que agem sobre ele (Sánchez et al, 1999b). Este processo é

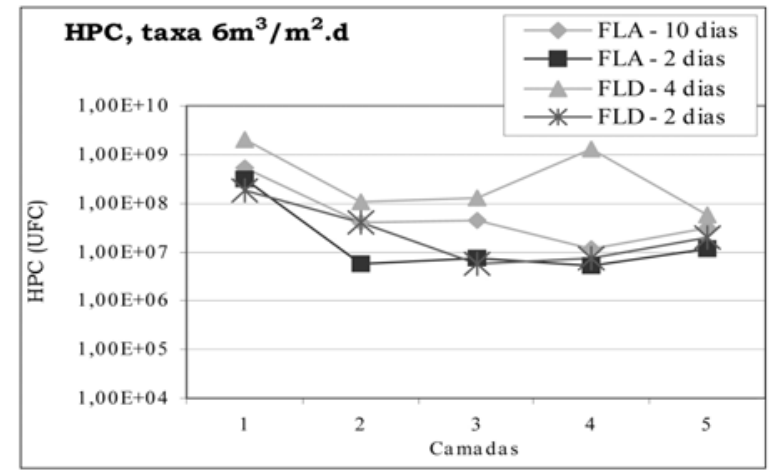

(a)

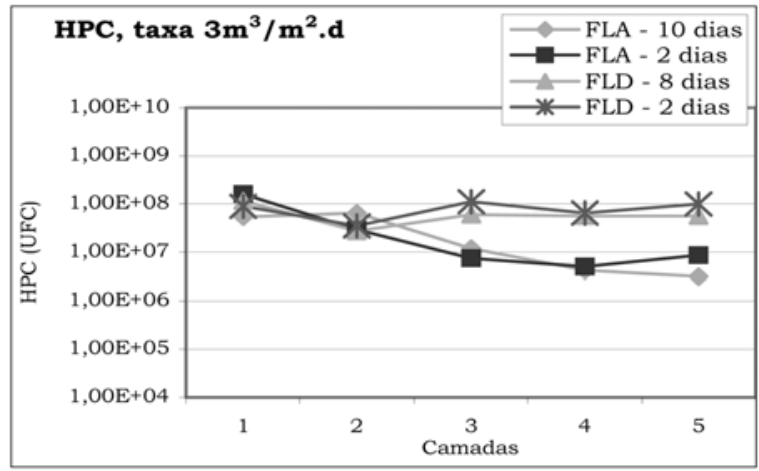

(b)

Figura 7 - Comparação entre os momentos de aņálișe da carreira e o sentido de fluxo nas duas taxas estudadas. (a) taxa de filtração: $6 \mathrm{~m} / \mathrm{m}$.d; (b) taxa de filtração: $3 \mathrm{~m} / \mathrm{m}$.d. 


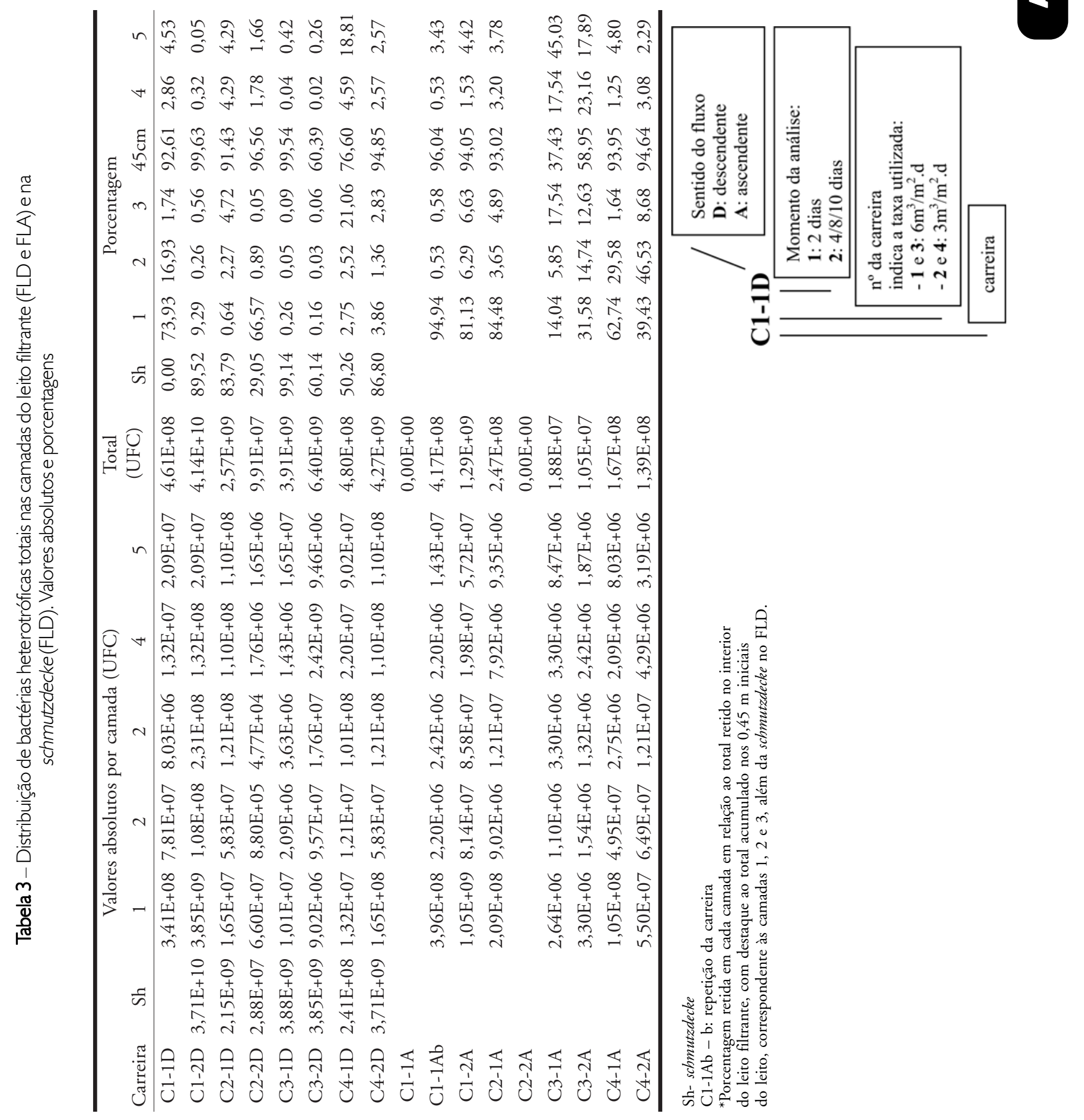


dinâmico no interior do filtro, ou seja, a qualquer momento uma parte do biofilme pode se desprender e ser transportado para trechos a jusante no leito filtrante, onde pode ser degradado ou liberado no efluente. Quanto mais ocupados os poros do leito filtrante, pelo crescimento da camada biológica, mais alta se torna a velocidade do escoamento, aumentando a tensão de cisalhamento que age sobre o biofilme, podendo culminar no seu desprendimento. Esse conjunto de fatores pode ter levado à detecção de concentraçôes maiores de bactérias em camadas mais profundas do leito, embora este fato só tenha sido observado em uma das duplicatas.

Além disso, é interessante notar que, no FLD, as duas camadas onde se percebeu maior penetração de bactérias foram aquelas onde a remoção deste indicador pela schmutzdecke foi bem inferior aos outros valores observados. Esta constatação pode levar a duas diferentes conclusões: (i) a schmutzdecke tem um papel essencial na eficiência de remoção de bactérias pelo filtro lento descendente; (ii) quando a schmutzdecke não se desenvolve a contento, pode ocorrer uma maior penetração de bactérias no interior do leito filtrante.

\section{(b) Remoção na schmutzdecke}

Foram observadas altas concentrações de bactérias heterotróficas totais na schmutzdecke, com exceção das situaçōes já mencionadas. Estas altas concentraçóes podem ser devidas tanto à grande capacidade de retenção da superfície do leito filtrante, como à conseqüente formação do biofilme, que, segundo alguns autores, tem papel essencial na remoção de patógenos no filtro (Huisman, 1982; Di Bernardo, 1993). De acordo com McNair et al (1987), a composição e a quantidade bacteriana da água bruta, bem como o tipo preferencial de alga que se desenvolve sobre o leito (unicelular ou filamentosa) irá determinar o tempo de formação e as características da schmutzdecke.

A Tabela 3 apresenta a concentração de HPC na schmutzdecke nas diferentes taxas e nos dois momentos de análise. De maneira semelhante ao que é observado no interior do leito, a taxa mais alta determina um acúmulo maior de bactérias do primeiro para o segundo momento, enquanto para a taxa mais baixa a diferença entre os dois momentos é muito pequena. Uma explicação possível é novamente o desenvolvimento de uma comunidade mais equilibrada com oito dias de carreira e taxa de $3 \mathrm{~m}^{3} / \mathrm{m}^{2}$.d.

\section{Distribuição de coliformes totais e E. coli}

Para estes parâmetros, a camada 1 apresentou-se em geral mais concentrada, com um decréscimo para a segunda camada (0,15-0,30 m); as camadas 3 e 4 foram quase sempre semelhantes, e a quinta um pouco menos concentrada que as anteriores. A camada 2 do FLD, sob taxa $6 \mathrm{~m}^{3} / \mathrm{m}^{2}$.d e 4 dias de análise, apresentou uma concentração ligeiramente maior de $E$. coli que a camada 1 , sendo que a mesma camada do FLD sob a taxa mais baixa também apresentou o mesmo padrão para ambos os parâmetros.

Considerando que o filtro no segundo momento de análise já apresenta uma certa maturidade, uma hipótese a ser considerada é a redução da concentração de bactérias coliformes aderidas por mecanismos de predação (principalmente por protozoários ciliados) e competição por alimento e espaço, uma vez que esta camada é a mais "populosa" no interior do leito filtrante. Um indício desta superatividade metabólica é o alto consumo de oxigênio nas primeiras camadas do leito filtrante, bem menos destacado nas camadas posteriores (Fox et al, 1984).

Sob a taxa de filtração mais alta, há um acúmulo de ambos os grupos nas camadas 1 e 2 , e mais notadamente na camada 5. Como já discutido previamente, a maturidade alcançada pelo leito filtrante durante a taxa de $6 \mathrm{~m}^{3} / \mathrm{m}^{2}$.d não é ainda a ideal, e o controle dos microrganismos aderidos ao biofilme não é totalmente satisfatório. Os últimos $0,5 \mathrm{~m}$ do filtro, de acordo com a literatura (Huisman, 1982; Bellamy et al, 1985; Di Bernardo, 1993), seriam os menos colonizados do leito filtrante, pois a carga de matéria orgânica e nutrientes que aflui a esta camada é muito reduzida, dificultando o estabelecimento da microfauna. Talvez por isso haja um acúmulo maior de bactérias coliformes e E. coli nesta camada, pois são menores as taxas de predação. Outra possível explicação para esta alta concentração pode ser o desprendimento de biofilme das camadas superiores que é levado até as partes mais profundas do filtro.

No FLA, ao contrário, para a taxa de $3 \mathrm{~m}^{3} / \mathrm{m}^{2}$.d houve uma acúmulo de bactérias aderidas do primeiro momento de análise (2 dias) para o segundo (10 dias). Novamente, a taxa mais alta $6 \mathrm{~m}^{3} / \mathrm{m}^{2} \cdot \mathrm{d}$ - determina uma distribuição menos uniforme no interior do leito filtrante.
Para E. coli, a média de remoção no FLD nos $0,45 \mathrm{~m}$ iniciais - 91,5\% - foi pouco menor que aquela encontrada para coliformes totais - 93,2\% - sendo que a carreira C4-1D novamente se apresentou atípica, com remoção bem inferior à média. Para o FLA, percebe-se mais uma vez uma grande variação entre os resultados, com a remoção variando entre 76,0 e $100 \%$. A baixa remoção observada para a carreira C4-1D talvez possa ser explicada pela baixa atuação de remoção na schmutzdecke, atípica para esta taxa, mesmo com período de tempo de desenvolvimento mais baixo.

Murtha e Heller (2003), ao avaliarem filtros pilotos com a mesma configuração, observaram que os $0,30 \mathrm{~m}$ iniciais eram responsáveis por mais de $98 \%$ da remoção de coliformes totais e $E$. coli, tanto no FLD quanto no FLA, sob diferentes taxas. O comportamento das camadas mais a jusante era sempre semelhante, independentemente da remoção nas camadas anteriores, do fluxo ou da taxa estudada. A diferença entre aquele estudo e o presente trabalho consiste da metodologia utilizada na avaliação da remoção em profundidade: aquele trabalho avaliou apenas a água intersticial em diferentes profundidades, desconsiderando os microrganismos aderidos e ainda viáveis, que podem alcançar o efluente pelos mecanismos de autocontrole da espessura do biofilme.

Algumas espécies de coliformes totais são capazes de se desenvolverem e multiplicarem em biofilmes aderidos, desde que existam condições ambientais adequadas, ou seja, matéria orgânica e nutrientes que possam dar suporte ao seu crescimento (WHO, 2004). Provavelmente, esses organismos passam a fazer parte da camada biológica aderida que se forma no interior do leito filtrante, o que poderia explicar as concentraçōes em maiores profundidades obtidas neste estudo.

$\mathrm{Na}$ schmutzdecke, observou-se que a distribuição de coliformes e $E$. coli foi similar ao padrão detectado para as bactérias heterotróficas totais, com acúmulo de organismos na taxa mais alta do primeiro para o segundo momento de análise e manutenção deste número de dois para oito dias na taxa de $3 \mathrm{~m}^{3} / \mathrm{m}^{2}$.d.

Já em relação ao efluente, foi possível observar que para a taxa de aplicação mais baixa $-3 \mathrm{~m}^{3} / \mathrm{m}^{2}$.d - o FLD conseguiu gerar concentrações não detectáveis de coliformes totais e $E$. coli, no segundo dia de análise (oito dias). Este resultado é 
esperado, uma vez que tanto taxas mais baixas quanto maior maturidade do leito filtrante são fatores determinantes da maior eficiência microbiológica do filtro lento (Bellamy et al, 1985; Di Bernardo, 1993; Murtha e Heller, 2003). Com dois dias de carreira e sob a taxa de $6 \mathrm{~m}^{3} / \mathrm{m}^{2}$.d, uma das duplicatas apresentou eficiência negativa para a remoção de $E$. coli, provavelmente devido às concentraçôes muito baixas deste parâmetro na água bruta. Para as outras situações estudadas, o filtro descendente apresentou eficiências de remoção acima de $98 \%$ para coliformes totais e de $97 \%$ para $E$. coli, mesmo quando a maturidade do filtro não era ideal. Isto reitera ainda mais a alta qualidade desta modalidade de tratamento na produção de água para consumo humano, mas alerta para a importância de se manter a desinfecção como pós-tratamento.

Para o FLA, por duas vezes a eficiência de remoção obtida foi inferior a 90\%, mas apenas em uma das duplicatas. Nas demais, os valores de eficiência superaram sempre a marca dos $90 \%$, sendo que a taxa mais baixa gerou efluentes ligeiramente melhores - com menor concentração de ambos os indicadores. Pesquisas anteriores a este estudo indicam que o filtro lento de fluxo ascendente exige um tempo um pouco maior para a geração de um efluente seguro, se comparado ao de fluxo descendente. Neste estudo, apenas uma das duplicatas da carreira de 10 dias sob a taxa de $3 \mathrm{~m}^{3} / \mathrm{m}^{2}$.d apresentou $100 \%$ de remoção de E. coli.

Sánchez et al (1999b) destacam que a concentração de coliformes fecais - e E.coli, em decorrência - no efluente é melhor indicador da maturidade biológica do filtro lento que a turbidez, uma vez que esta se estabiliza muito mais rapidamente no efluente. Os autores afirmam que o tempo de maturação pode ser estimado qualitativamente pela concentração de coliformes termotolerentes no efluente logo após a limpeza: quanto maior esta concentração, maior será o período necessário para que o filtro alcance a maturidade.

\section{Distribuição de bactérias esporuladas}

\section{(a) Remoção em profundidade}

A Figura 8 ilustra a distribuição das bactérias esporuladas - esporos de bactérias anaeróbias (EBAN) e Clostridium perfringens, esporos de bactérias aeróbias
(EBAR) e Bacillus subtilis - no interior dos filtros de fluxo descendente.

$\mathrm{O}$ que se torna bem evidente nos FLD é a ausência de um padrão geral para a distribuição de esporos de bactérias aeróbias (EBAR) e Bacillus subtilis no interior do leito filtrante. Ao contrário do observado para outros parâmetros, não há uma concentração maior nos $0,15 \mathrm{~m}$ iniciais do leito filtrante, nem uma redução da concentração com a profundidade. É interessante observar, no entanto, que não existe uma acumulação expressiva destes dois parâmetros do primeiro (2 dias) para o segundo momento de análise (4/8 dias), indicando que possa haver um controle da retenção destes esporos aeróbios no interior do leito de areia.

Com relação aos esporos de bactérias anaeróbias e Clostridium perfringens, pode-se perceber um acúmulo um pouco diferenciado na primeira camada, com uma tendência sutil de redução da concentração com o aumento da profundidade. No entanto, sob a taxa de $3 \mathrm{~m}^{3} / \mathrm{m}^{2}$.d com dois dias de análise, há uma ligeira redução da quantidade de esporos da primeira para terceira camada, mas esta volta a subir na quarta e mais ainda nos 0,15 $\mathrm{cm}$ finais do leito. Da mesma maneira que observado para os esporos aeróbios, não houve uma acumulação significativa do primeiro para o segundo dia de análise sob ambas as taxas, sugerindo também um controle destes microrganismos no leito filtrante.

Para o FLA são válidas as mesmas observaçōes realizadas para o FLD quanto à ausência de padrôes de distribuição de esporos de bactérias aeróbias e Bacillus subtilis no interior do leito filtrante. Notase uma quantidade consideravelmente menor destas bactérias no interior do leito filtrante para a taxa de $3 \mathrm{~m}^{3} / \mathrm{m}^{2}$.d, com dez dias de carreira. Coerentemente, a água afluente às duas carreiras realizadas sob estas condições apresentou concentraçôes cerca de 2 a 3 log inferiores à média das outras carreiras, resultando em um menor aporte de bactérias esporuladas no interior do filtro e conseqüente menor acumulação.

Em relação à retenção nos $0,45 \mathrm{~m}$ iniciais do leito filtrante para os esporos de bactérias anaeróbias, variou muito entre as carreiras realizadas - entre $70,1 \%$ e 95,1\% para o FLD (com exceção de uma carreira com maior taxa e maior maturidade, cuja retenção nestas camadas foi de $56,1 \%$, atípica) e $65,8 \%$ e $95,4 \%$ para o FLA (com exceção de uma carreira com menor taxa e menor maturidade, cuja re- tenção foi de $40,0 \%$, atípica). Já para Clostridium perfringens, a retenção média nos primeiros $0,45 \mathrm{~m}$ do leito filtrante foi de $91,02 \%$ para ambos os fluxos, chegando a $100 \%$ em algumas carreiras.

Tanto para os esporos de bactérias aeróbias como para Bacillus subtilis a retenção nos $0,45 \mathrm{~m}$ iniciais variou enormemente de uma carreira para outra, sem apresentar nenhum padrão relacionado à taxa de filtração, ao tempo de carreira ou ao sentido de fluxo.

Outro ponto a ser ressaltado é que os esporos, sejam aeróbios ou anaeróbios, tendem a apresentar comportamento semelhante ao de uma partícula inerte, diferente do observado para bactérias como coliformes totais, mas teoricamente semelhante aos cistos e oocistos de protozoários. No entanto, a concentração das bactérias aeróbias esporuladas na água bruta chega a ser 5 log mais alta que as de Cryptosporidium. Essa concentração, segundo Bellamy et al (1985) tem efeito determinante na concentração no efluente, indicando que a concentração afluente também surte efeito sobre a dinâmica destas bactérias no interior do filtro. Murtha e Heller (2003), porém, observaram que variações na turbidez afluente não afetam diretamente a turbidez do efluente, entretanto trabalhando com filtros lentos de areia já maduros biologicamente. Nieminski et al (2000) confirmam o comportamento destes microrganismos como partícula inerte, ao afirmarem que, ao longo de tratamentos por filtração rápida, a remoção de esporos de bactérias aeróbias e $B$. subtilis é conseqüência de ações físicas, com pouca alteração na viabilidade e na forma destes esporos. Ponto a ser ainda elucidado é se o mesmo pode ser assumido na filtração lenta, sobretudo para os esporos de bactérias aeróbias, dado que outra pesquisa encontrou resultado que permite presumir crescimento da população de microrganismos no processo (Vieira, 2002).

\section{(b) Remoção na schmutzdecke}

A Figura 9 permite observar que, sob a taxa mais baixa, há um acúmulo maior de EBAR e B. subtilis na schmutzdecke, embora o aporte tenha sido menor. Isso se configura como uma nova indicação de que taxas mais altas implicam em uma penetração maior de partículas no interior do leito filtrante. E interessante observar que para todos os parâmetros (exceto B. subtilis sob a taxa de $3 \mathrm{~m}^{3} / \mathrm{m}^{2}$.d) há um ligeiro acúmulo na 


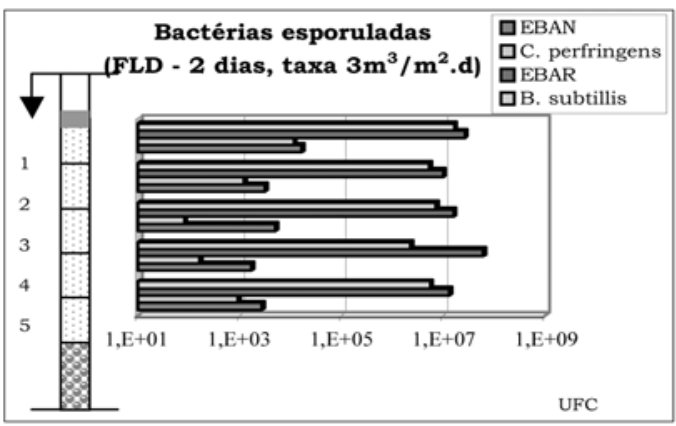

(a)

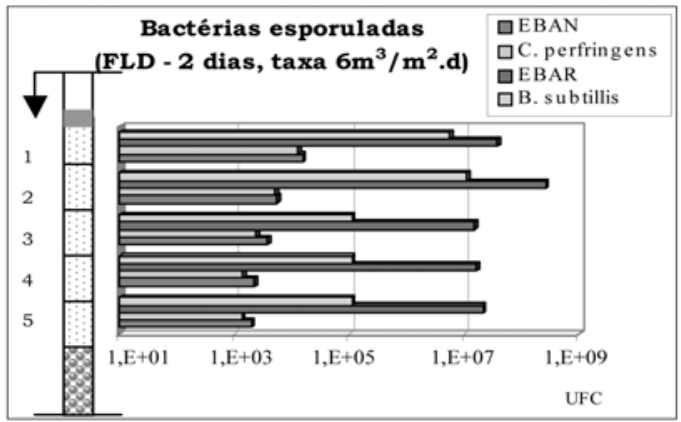

(c)

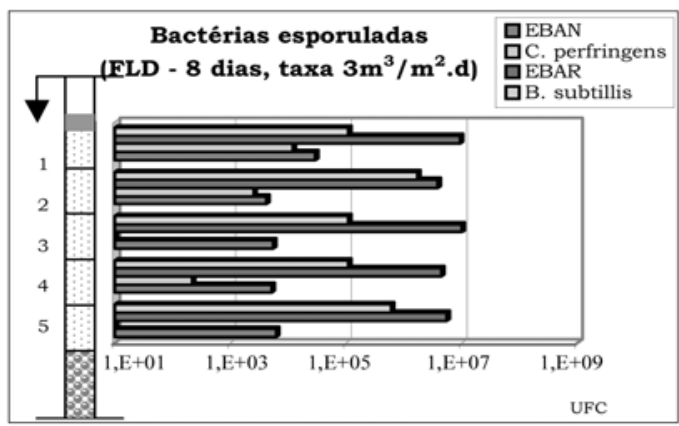

(b)

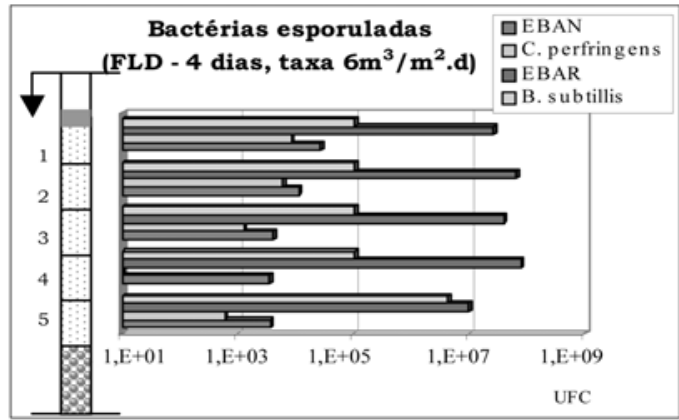

(d)

Figura 8 - Quantidade de bactérias esporuladas no interior do FLD. (a) taxa $6 \mathrm{~m}^{3} / \mathrm{m}^{2}$.d, 2 dias; (b) taxa $6 \mathrm{~m} / \mathrm{m}$.d, 4 dias; (c) taxa $3 \mathrm{~m} / \mathrm{m}^{2}$.d, 2 dias; (d) taxa $3 \mathrm{~m} / \mathrm{m}$.d, 8 dias

schmutzdecke do primeiro para o segundo momento de análise.

No entanto, ao se observarem os valores percentuais de retenção destes parâmetros pela schmutzdecke, percebe-se que a camada biológica sobre o leito filtrante pouco contribui para a remoção total no interior do filtro. Apenas para $C$. perfringens a camada mais desenvolvida contribuiu para uma alta remoção $92,11 \%$.

\section{(c) Efluente}

A mesma irregularidade na dinâmica de esporos de bactérias aeróbias e $B$. subtilis no interior do leito filtrante pode ser observada no efluente dos FLD e FLA. Os valores obtidos no efluen te variaram de $1,0 \times 10^{1}$ a $1,60 \times 10^{6} \mathrm{UFC} / 100 \mathrm{~mL}$ para EBAR e $1,0 \times 10^{1}$ a 3,10x $10^{5} \mathrm{UFC} / 100 \mathrm{~mL}$ para B. subtilis. Não foi possível encontrar nenhuma relação entre as eficiências de remoção e os sentidos de fluxo, taxa de filtração ou momento de análise da carreira.

Já com relação aos esporos de bactérias anaeróbias e $C$. perfringens, os filtros apresentaram um comportamento muito mais uniforme. Os primeiros só ocorreram no efluente nos primeiros momentos de análise, principalmente sob taxa mais alta $-6 \mathrm{~m}^{3} / \mathrm{m}^{2}$.d. C. perfringens só foi detectado no efluente duas vezes,

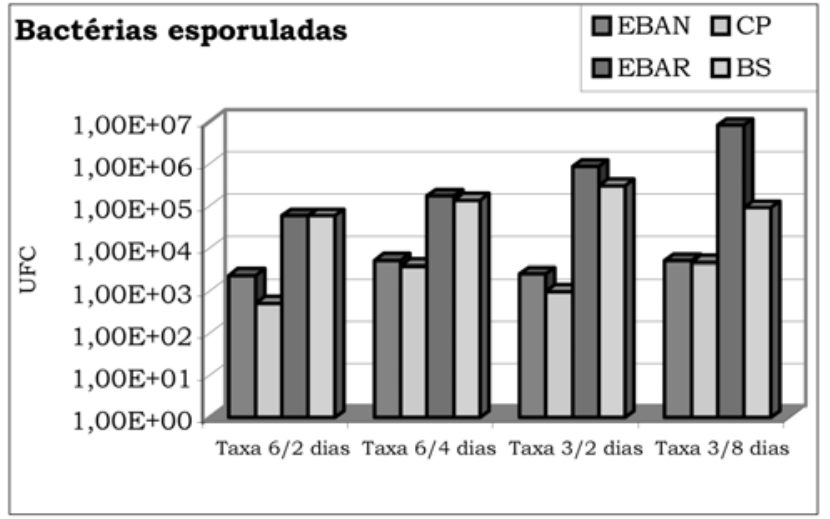

Figura 9 - Quantidade de bactérias esporuladas

(EBAN e C. perfringens, EBAR e B. subtilis) na schmutzdecke

ambas no primeiro momento de análise do FLD, uma sob taxa maior e outra sob a taxa menor. Este padrão foi mais coerente que o encontrado para cisto de Giardia e oocistos de Cryptosporidium (Brito, 2002).

Nieminsky et al (2000), avaliando esses quatro parâmetros como indicadores da qualidade do tratamento, observaram que esporos de bactérias anaeróbias e C. perfringens apresentam-se ausentes ou em concentração muito baixa no efluente, enquanto esporos de bactérias aeróbias e B. subtilis, apesar de serem removidos em grande proporção (até $4 \log$ ), sempre são detectados no efluente, permitindo uma melhor avaliação do tratamento como um todo, não apenas com relação à remoção de patógenos.

\section{CONCLUSÕES}

O trabalho realizado permite as seguintes conclusões preliminares:

- a maturidade biológica do leito filtrante, entendida como o equilíbrio da comunidade que se forma sobre o leito de areia, parece ser menos favorecida pela taxa mais alta de filtração e pelo fluxo ascendente; 
- para coliformes totais e E. coli o sentido de fluxo parece influenciar a sua distribuição apenas sob taxas de filtração mais altas, enquanto para as bactérias esporuladas não foram observadas diferenças na distribuição em nenhuma das situações estudadas;

- os 0,45 m iniciais do leito filtrante são importantes na remoção de microrganismos na filtração lenta, sob as condições estudadas, mas a remoção não se restringe apenas a estas camadas, sendo que para todos os indicadores de qualidade de água avaliados pode-se observar retenção nas camadas de 0,45-0,60 m e de 0,60-0,75 m, em diferentes proporções entre as carreiras;

- a schmutzdecke parece apresentar papel efetivo na remoção de microrganismos indicadores apenas quando bem desenvolvida, afetando de maneira diferenciada a dinâmica dos diversos parâmetros aqui estudados, mas sem um padrão bem definido para essa interferência;

- a avaliação das quantidades dos microrganismos indicadores e dos indicadores físico-químicos no interior das camadas do leito filtrante, nos dois fluxos estudados, dá uma indicação de que a camada suporte exerce algum papel na retenção de sólidos e microrganismos no fluxo ascendente.

\section{AGRADECIMENTOS}

Os autores gostariam de reconhecer e agradecer a contribuição da FAPEMIG e da FUNASA, por meio do Projeto VIGISUS, pelo apoio financeiro à pesquisa; do CNPq, pela concessão de bolsas, e da FUNED, pelo suporte laboratorial e analítico.

\section{REFERÊNCIAS}

AMERICAN PUBLIC HEALTH ASSOCIATION I AMERICAN WATER WORKS ASSOCIATION I WATER ENVIRONMENT FEDERATION. Standard methods for the examination of water and wastewater. 20 ed. Washington: APHA/AWWA/ WEF, 1998.

ARAUJO, et al. Evaluation of fluorogenic TSC agar for recovering Clostridium perfringens in groundwater samples. Water Science and Technology, v.43, n.12. p.201-204, 2001.

BARBEAU, B. et al. Examining the use of aerobic spore-forming bacteria to assess the efficiency of chlorination. WaterResearch, v.33, n.13, p. 2941-2948, 1999.

BELLAMY, W.D.; HENDRICKS, D.W.; LOGSDON, G.S. Slow sand filtration: influences of selected process variables. Journal American Water Works Association, v.77 n.12, p.62-66, Dez. 1985.
BRASIL. Ministério da Saúde. Portaria n. 518, de 25 de março de 2004. Estabelece os procedimentos e responsabilidades relativas ao controle e vigilância da qualidade da água para consumo humano e seu padrão de potabilidade, e dá outras providências. Diário Oficial da União, Brasília, v.141, n.59, p.266, Seção 1. 25 mar. 2004.

BRITO, L. L. A. Dinâmica de Cryptosporidium sp e de indicadores de qualidade da água ao longo da profundidade de filtros lentos de areia. Dissertação (Metrado em Saneamento, Meio Ambiente e Recursos Hídricos) - Escola de Engnharia, Universidade Federal de Minas Gerais, Belo Horizonte. 2002.

DI BERNARDO, L. Métodos e técnicas de tratamento de água, volume II.Rio de Janeiro: ABES, 503p. 1993.

DI BERNARDO, L., BRANDĀO, C.C.S., HELLER, L.. Tratamento de águas de abastecimento por filtração em múltiplas etapas. Rio de Janeiro: ABES, 114p. 1999.

ELLIS, K.V.; AYDIN, M.E. Penetration of solids and biological activity into slow sand filters. Water Research, v.29, n.5, p.1333-1341, 1995.

FERGUSON, C.M. et al. Relationships between indicators, pathogens and water quality in an estuarine system. Water Research, v.30, n.9, p.2045-2054, Set. 1996.

FOX, K.R. et al. Pilot-plant studies of slow-rate filtration. Journal American Water Works Association, v.76 n.12, p.62-68, Dez. 1984.

HUISMAN, L. Research and demonstration project on slow sand filtration. AIDIS Congress Held in Panamá. AIDIS, 99p. 1982.

LLOYD, B. The construction of a sand profile sampler: its use in the study of the Vorticella populations and the general interstitial microfauna of slow sand filters. Water Research, v.7, p.963973, 1973.

McCONNEL, L.J. Evaluation of slow rate sand filtration process for treatment of drinking water containing viruses and bacteria. Utha State University, USA, 1984.

McNAIR, D.R. et al. Schmutzdecke characterization of Clinoptile-amended slow sand filtration. Journal American Water Works Association, v.79, n.12, p.74-81, Dez. 1987.

MURTHA, N.A., HELLER, L. Avaliação da influência de parâmetros de projeto e das caracteristicas da água bruta no comportamento de filtros lentos de areia. Revista Engenharia Sanitária e Ambiental, v.8, n.4, p.267-277, 2003.

NIEMINSKI, E.C.; BELLAMY, W.D.; MOSS, L.R. Using surrogates to improve plant performance. Journal American Water Works Association, v.92 n.3, p.67-78, Mar. 2000.

POYNTER, S.F.B. \& SLADE, J.S. The removal of viruses by slow sand filtration. Progress in Water Technology, v.9, p.75-88, 1977.

RICE; E.W.et al. Evaluating plant performance with endospores. Journal American Water Works Association, v.88 n.9, p.122-130, Set. 1996.

SÁNCHEZ, L.D.; LATORRE, J.; GALVIS, G. Comportamiento de la poblacion de algas y protozoos despues de la limpieza de la biomembrana en un filtro lento en arena. In: $20^{\circ}$ CONGRESSO BRASILEIRO DE ENGENHARIA SANITÁRIA E AMBIENTAL,
1999, Rio de Janeiro. Anais... Rio de Janeiro: ABES, 1999a.

SÁNCHEZ, L.D.; LATORRE, J.; GALVIS, G. Periodo de maturacion: efecto de la limpieza de la biomembrana en un filtro lento de arena. In: $20^{\circ}$ CONGRESSO BRASILEIRO DE ENGENHARIA SANITÁRIA E AMBIENTAL, 1999, Rio de Janeiro. Anais... Rio de Janeiro: ABES, 1999b.

SEELAUS, T.J.; HENDRICKS, D.W.; JANONIS, B.A. Design and operation of a slow sand filter. Journal American Water Works Association, v.78 n.12, p.35-41, Dez. 1986.

TIMMS, S; SLADE, J.S.; FRICKER, C.R. Removal of Cryptosporidium by slow sand filtration. Water Science and Technology, v.31, n.5-6. p.81-84, 1995.

VARGAS, L.C. Filtración lenta y dinámica como desinfectantes. In: SIMPOSIO REGIONAL SOBRE CALIDAD DEL ÁGUA: DESINFECCIÓN EFECTIVA, Lima, 27-29 de Octubre, 1999.

VIEIRA, M. B. C. M. Avaliação da eficiência de processos de tratamento de água de abastecimento na remoção de oocistos de Cryptosporidium sp. e cistos de Giardia spp. Tese (Doutorado em Ciência Animal) - Escola de Veterinária, Universidade Federal de Minas Gerais, Belo Horizonte. 2002 .

WORLD HEALTH ORGANIZATION. Guidelines for drinking water quality; Recommendations. 3ed. Geneva: WHO, Vol. 1. 494p. 2004.

Endereço para correspondência:
Léo Heller
Departamento de Engenharia
Sanitária e Ambiental - UFMG
Av. Contorno, 842/7/5
30110-060
Belo Horizonte - MG - Brasil
heller@desa.ufmg.br 